\title{
La educación griega y sus fuentes: aproximación a las épocas clásicas y helenísticas en Atenas
}

\author{
The greek education and its sources: \\ approximation to classic and hellenstic times in Athens
}

\author{
DAVID ESPINOSA ESPINOSA ${ }^{1}$
}

\begin{abstract}
RESUMEN
La búsqueda de fuentes para el estudio de la educación griega, siglos v y IV a.C.,

ha revelado un amplio repertorio de trabajos a través de los cuales comprender el pensamiento pedagógico griego. La conformación del Estado ateniense, durante el siglo $v$ a.C., constituyó el punto de partida de un gran movimiento educador, debiéndose realizar su investigación mediante el estudio y análisis de las fuentes literarias, arqueológicas y epigráficas.

PALABRAS CLAVE: Fuentes documentales; Filosofía de la educación; Paideia; Sofistas; Platón; Aristóteles; Atenas; Grecia.

\footnotetext{
${ }_{1}$ Becario Predoctoral Programa FPU (MEC). Departamento de Historia Antigua.

Facultad de Geografía e Historia. Universidad Complutense de Madrid. $\mathrm{C} /$ Profesor Aranguren $\mathrm{s} / \mathrm{n}$.

Ciudad Universitaria, 28040 Madrid. davidespinosa@ghis.ucm.es.
}

\section{ABSTRACT}

Search of sources for the study of the Greek education, in the 4th and 5th centuries B.C., has revealed a wide collection of papers across which understanding the pedagogic Greek thought. The shape of the Athenian State, during the 5th century B.C., constituted the beginning of a great educational movement. Its research must be realized by means of the study and analysis of the literary, archaeological and epigraphic evidences.

KEYWORDS:

Documentary sources; Philosophy of education; Paideia; Sophists; Plato; Aristotle; Athens; Greece. 


\section{ESTADO ACTUAL DE LA INVESTIGACIÓN: LA EDUCACIÓN GRIEGA.}

La búsqueda, análisis y sistematización de fuentes, ya sean primarias o secundarias, para el estudio de la Educación griega en época clásica y helenística, ha revelado un amplio repertorio de trabajos, de considerable antigüedad, a través de los cuales acometer la aproximación y comprensión de las líneas fundamentales de pensamiento pedagógico griego, y de los principales logros en materia educativa. Pero este vasto cuerpo documental resulta engañoso en el momento en el que penetramos en su interior, observando que la mayor parte de las obras resultan ser poco precisas y estar reducidas, esencialmente, al estudio de dos figuras paradigmáticas de la instrucción griega: Platón y Aristóteles. De ellos, los estudios amplios publicados en libros son casi inexistentes, predominado breves monografías divulgadas en revistas o publicaciones periódicas. También podrían añadirse a este elenco de producciones bibliográficas las historias generales de la educación y de la pedagogía, en las que nunca suele faltar una referencia mayor o menor, a veces sintética, a sus reflexiones intelectuales. Ejemplo de ellas son las obras de Luzuriaga (1984), Fullat (1992), Mas (2003) o Pailler y Payen (2004)2. En general, no suponen ni pretenden ser una contribución a la investigación en el tema, pero nos pueden ser de gran utilidad.

Más interesantes, a mi juicio, son las historias de la educación en la Antigüedad, que, por tener un marco más reducido de referencia, su profundización y aportación es superior. Deben ser destacadas, entre ellas, la de Galino (1982) y Marrou $(1985)^{3}$, que, a pesar de su poca amplitud, no dejan de ser un buen estudio didáctico y divulgador, conservando su rigor crítico y científico.

En esta misma línea, deben ser mejor considerados los trabajos cuyo objeto ha sido la historia de la Educación griega, algunos de los cuales, como el de Lynch (1972), Egido y Hernández (1990), Robb (1994), Calvo (1995), Jaeger (1996), o Too $(2001)^{4}$, aun circunscribiéndose al fenómeno general de la paideia, referida a los ideales de la cultura griega más que al marco estricto de la educación, no pueden desconocerse. Dentro de estas mismas coordenadas, pueden destacarse obras como las de Girad (1891), Benetti Brunelli (1939), Morrison (1948), Anderson

2 Luzuriaga, L.: Historia de la educación y de la pedagogía, Buenos Aires, Losada, 1984; Fullat, O: Filosofías de la educación: paideia, Barcelona, CEAC, 1992; Mas Torres, S.: Ethos y polis: una historia de la filosofía práctica en la Grecia clásica, Tres Cantos, Istmo, 2003; Pailler, J. M. y Payen, P.: Que reste-t-il de l'education classique?: relire «le Marrou», histoire de l'éducation dans l'Antiquité, Tolousse, Presses Universitaires de Mirail, 2004.

3 Galino, M. A.: Historia de la Educación: Edades Antigua y Media, Madrid, Gredos, 1982; Marrou, H. I.: Historia de la Educación en la Antigüedad, Madrid, Akal, 1985.

4 Lynch, J. P.: Aristotle's school: a study of a Greek educational institution, Los Ángeles, University of California, 1972; Egido Gálvez, I. y Hernández Blasi, C.: «La educación en Grecia», Cuadernos de Pedagogía, 187, (1990), pp. 88-96; ROBB, K.: Literacy and paideia in ancient Greece, Oxford, Oxford University Press, 1994; Calvo Martínez, T.: De los sofistas a Platón: política y pensamiento, Madrid, Ediciones Pedagógicas, 1995; Jaeger, W.: Paideia: Ios ideales de la cultura griega, Madrid, F.C.E., 1996; Too, Y. L.: Education in Greek and Roman antiquity, Leiden, Brill, 2001. 
(1964), Beck (1964), o Stockmeier (1967)5 que, recogiendo perspectivas generales de la educación griega, estudian aspectos concretos de la educación ateniense.

Existen, por otra parte, monografías que describen y estudian aspectos más profunda y directamente relacionados con la educación griega. Temas como la efebía, las instituciones educativas, la Academia, el deporte, o la gimnasia, en modo alguno deben ser obviados a la hora de un estudio integral de la educación griega. Así, sobre la efebía son ya clásicos los trabajos de Pélékidis (1962), Dumont (1968) y Reinmuth $(1971)^{6}$, enfocados desde una perspectiva estrictamente histórica y recogiendo, en el caso de Reinmuth, un vasto corpus documental de carácter epigráfico. En relación con los aspectos institucionales de la educación, son interesantes los estudios de Bossell (1896), Landsberg (1926), Herter (1952), Armtrong (1953), Seel (1953), Isnardi (1959) y Dorandi (1994)

No deberían ser orillados los trabajos que tratan de la familia y la infancia, siendo representativos los de Lacey (1968), Golden (1990) y Cox (1998)8. Lo mismo cabe decir de las monografías relativas a los temas del deporte, el juego, la gimnasia o la música, aspectos relacionados con la práctica educativa griega. En este sentido, pueden reseñarse los trabajos de Forbes (1929), Moutsopoulos (1959), Harris (1972), Patrucco (1972), Anderson (1966) y Phillips y Pritchard (2003)9.

De mayor importancia son las investigaciones relativas a los conceptos de areté y kalokagathia. Un ejemplo referido a Patón y Aristóteles lo tenemos en la obra de Kraemer (1959) ${ }^{10}$, un estudio evolutivo de ambos conceptos que nos acerca al conocimiento de los objetivos educativos griegos.

5 Girard, P.: L’éducation athénienne, París, 1891; Benetti Brunelli, V.: Il pensiero educativo della Grecia, Roma, 1939; Morrison, J. S.: «An introductory chapter in the history of Greek education», Durham Univ. Juorn., 41, (1948), pp. 55-63; Anderson, W.: Man's quest for political knowledge. The study and teaching of politics in ancient times, Minneapolis, Univ. Minnesota Pr., 1964; Beck, F. A. G.: Greek education 450-350 B.C., London, Methuen, 1964; Stockmeier, P.: «Glaube und Paideia. Zur Begegnung von Christentum und Antike», ThQ, CXLVII, (1967), pp. 432-452.

6 Pélékidis, C.: Histoire de l'éphébie attique des origines a 31 avant Jésuschrist, París, Editions E. De Boccard, 1962; Dumont, A.: Essai sur l'éphébie attique, Osnabrück, Otto Zeller, 1968; Reinmuth, O. W.: The Ephebic inscrptions of the fourth century B.C., Leiden, Brill, 1971.

7 Bossel, F. W.: The School of Plato, its origin, developement, London, 1896; Landsberg, P. L.: La Academia Platónica, Madrid, Rev. de Occidente, 1926; Herter, H.: Platons Akademie, Univ. Bonn, 1952 Armstrong, E. B.: Plato's Academy, Leeds Philos. Soc., 1953; Seel, O.: Die Platonische Akademie, Sttutgart, 1953; Isnardi, P. M.: «Studi recenti e problemi aperti sulla struttura e la funzione delle prima Accademia platonia», RSI, LXXI, (1959), pp. 271-291; Dorandi, T.: «La Academia de Platón a Antilo: estructura, historia y pensamiento», Endosa, 3, (1994), 147-163.

8 W. K. Lacey (1968): The family in classical Greece, London, Thames and Hudson; M. Golden (1990): Children and childhood in classical Athens, Baltimore, Johns Hopkins University Press; Ch. A. COX (1998): Household interests: property, marriage strategies, and family dynamics in ancient Athens, Princeton, Princeton University Press.

9 G. A. Forbes (1929): Greek Physical Education, New York; E. Moutsopoulos (1959): La musique dans l'oeuvre de Platon, París, P.U.F.; HARRIS, H. A.: Sport in Grece and Rome, Thames and Hudson, 1972; Patrucco, R.: Lo sport nella Grecia antica, Firenze, L.S. Olschki, 1972; Anderson, W.: Ethos and education in Greek music. The evidencie of poetry and philosophy, Cambridge, Harvard University, 1966; Phillips, D. y Pritchard, D.: Sport and festival in the ancient Greek world, London, Classical Press of Wales, 2003.

10 Kraemer, H. J.: Areté bei Platon und Aristoteles. Zum Wesen und zur Geschichte der platonischen Ontologie, Heidelberger Akad, phil-his KI, 1959. 
Es necesario destacar, tanto por el número como por la calidad de algunos trabajos, las obras alusivas al pensamiento y teoría educativa en personalidades como Platón, Isócrates y Aristóteles. Los estudios que tienen como tema la filosofía y dialéctica platónica quedan ampliamente representados por las obras de autores como Burnet (1920), Dies (1935), Robin (1935), Goldschimidt (1947), Robinson (1953), Lodge (1956), Guthrie (1967), Moreau (1967), Schaerer (1969) o Stenzel $(1973)^{11}$. Un hecho similar ocurre con los trabajos centrados en el concepto platónico de educación, abordado por investigadores como Friedlander (1928), Bury (1937), Barrington (1950), Librizzi (1950), Lasso (1966), Rabbow (1970) o Rodríguez Adrados (1985) ${ }^{12}$.

Respecto al estudio del pensamiento isocrático y aristotélico, sobre la educación, el número de obras es inferior, siendo necesario señalar trabajos como los de Lynch (1972), Cappelletti (1976), Oreja (1992), Poulakos y Depew (2004) ${ }^{13}$.

Por último, en relación con el movimiento sofístico, el volumen de trabajos es muy limitado, destacando sobre el resto estudios como los de Kerferd (1981), Alegre Gorri (1986), Plácido (1991) y Calvo (1995) ${ }^{14}$, siendo de vital conocimiento para su exploración la compilación de testimonios y fragmentos editada por Gredos y comentada por Antonio Melero Bellido (1996) ${ }^{15}$.

Por otra parte, la investigación en torno al pensamiento educativo griego, en los siglos $v$ y IV a.C., debe realizarse mediante el estudio y análisis de un amplio espectro de fuentes, literarias, arqueológicas y epigráficas. Debido a su variedad tipológica, la información proporcionada es compleja y de gran valor histórico, posibilitando la construcción de una completa secuencia cultural que permite comprender el proceso educativo de una manera global.

11 Burnet, J.: Greek Philosophy. Thales to Plato, London, 1920; Dies, A.: Platon, París, 1935; Robin, L.: Les grands philosophes. Platon, París, Alcan, 1935; Goldshmidt, V.: Les Dialogues de Platon. Structure et Méthodes dialectiques, París, P.U.F., 1947; Robinson, R.: Plato's Earlier Dialectic, Oxford, 1953; Lodge, R. C.: The phylosophy of Plato, London, 1956; Guthrie, W. K. C.: The Greek Philosophers. From Thales to Aristotle, London, Methuen, 1967; Moreau, J.: Le sens du platonisme, París, Les Belles Lettres, 1967; Schaerer, R.: La question platonicienne. Étude sur les rapports de la pensée et de l'expression dans les Dialogues, Université de Neûchatel, Neûchatel, 1969; Stenzel, J.: Plato's Method of Dialectic, New York, Arno Press, 1973.

12 Friedlander, P.: Platon, Eidos, Paideia, Dialogos, Berlín, Leipzig, 1928; Bury, R. G.: «The Theory of education in Plato's Laws, Rev. Ét. Grecques, 50, (1937), pp. 304-320; Barrington, L.: «Plato's theory of education», CL. Journ, 4, (1959), pp. 23-35; Librizzi, C.: Il problemi fondamentali della filosofia di Platone, Padova, 1950; Lasso de la Vega, J. S.: Ideales de la formación griega, Madrid, Rialp, 1966; Rabbow, P.: Paidagogia. Die Grundlegung der abendländischen Erziehungskunst in der Sokratik, Gotinga, 1970; Rodríguez Adrados, F.: «Platón y la reforma del hombre», Taula. Quaderns de Pensament, 3, (1985), pp. 7-26.

${ }^{13}$ Lynch, J. P., Op. cit.; Cappelletti, A. J.: «Ética y política en Aristóteles», Pensamiento: Revista de Investigación e Información filosófica, vol. 32, n. ${ }^{\circ} 127,(1972)$, pp. 323-328; Oreja, F.: «Aristóteles y la Retórica», Revista de Filosofía, 5 (8), 1992, pp. 419-427; Poulakos, T. y Depew, D.: Isocrates and civil education, Austin, University of Texas Press, 2004.

${ }_{14}$ Kerferd, G. B.: The sophistic movement, Cambridge, University, 1981; Alegre Gorri, A.: La sofística y Sócrates: ascenso y caída de la polis, Barcelona, Montesinos, 1986; Plácido, D.: «La ciudad de Sócrates y los sofistas: integración y rechazo», en J. Alvar y F. Gascó, Heterodoxos, reformadores y marginados en la Antigüedad clásica, 1991, pp. 13-28; Calvo Martínez, T.: De los sofistas a Platón: política y pensamiento, Madrid, Ediciones Pedagógicas, 1995.

15 Melero Bellido, A.: Sofistas: testimonios y fragmentos, Madrid, Gredos, 1996. 
En cuanto a las fuentes literarias, son numerosos los textos, de diferente género, que proporcionan información y hacen referencia a determinados aspectos del pensamiento y de la práctica educativa griega. Es necesario destacar, en primer lugar, las obras de Homero y Hesíodo, fundamentales para el conocimiento de la práctica aristocrática durante la época arcaica. En segundo lugar, autores como Esquilo, Sófocles, Eurípides, Aristófanes y Tucídides contribuyen, en mayor o menor medida, al conocimiento de aspectos cotidianos del proceso e ideal educativo griego. En tercer y último lugar, para conocer los principios filosóficos de la educación griega son imprescindibles las obras de Platón, Isócrates y Aristóteles, legado pedagógico de incalculable valor y base sólida de los posteriores desarrollos educativos.

Las fuentes arqueológicas, susceptibles de estudio y análisis, comprenden un vasto conjunto de restos cerámicos de diverso carácter. En primer lugar, grafitos y óstraka son válidos para realizar la reconstrucción de los niveles de alfabetización de la población griega. Revelan en qué medida estaba generalizado el hábito de la escritura. Por otra parte, son numerosos los restos de cerámica pintada que muestran escenas, detalladas, de la actividad pedagógica de los niños y niñas, así como momentos de su infancia y su adolescencia, siendo fundamentales para analizar los hábitos y las costumbres existentes entre los grupos sociales de la población.

Por último, las fuentes epigráficas hacen mención a la institución de la efebía, aportando valiosa información sobre su articulación y práctica.

\section{ESBOZO HISTÓRICO DE LA EDUCACIÓN GRIEGA EN ATENAS: PAIDEIA Y POLITEIA ${ }^{16}$}

A pesar de sus muchos éxitos, la extensión de la «alfabetización y escolarización» griegas ${ }^{17}$, a lo largo de los siglos V, IV y III a.C., siguió siendo una operación limitada, caracterizada por la falta de valoración general de su finalidad global, y dificultada por el estado embrionario de la teoría de la educación. Con fondos insuficientes, con unos marcos conceptuales de corto alcance, con frecuencia ineptos desde un punto de vista «administrativo», y basados en las estructuras clásicas vigentes, las iniciativas estatales fueron meras utopías.

La educación, entendida como el medio que conecta al ser humano con su grupo en relación recíproca, establece el procedimiento por el cual el individuo se aproxima al ideal de prototipo que la sociedad reclama en cada momento. Constituye el proceso de transmisión y asimilación de costumbres, normas, conocimientos, técnicas e ideas, mediante el cual cada sociedad incorpora a quienes se inte-

16 Paideia, del griego $\pi \alpha \iota \delta \varepsilon \iota$, , «educación», «formación». Politeia, del griego $\pi \mathrm{o} \lambda \iota \tau \varepsilon \alpha$, «régimen político», «organización social», «constitución».

17 Havelock, E. A.: La musa aprende a escribir. Reflexiones sobre oralidad y escritura desde la Antigüedad hasta el presente, Barcelona, Paidós, 1996. 
gran en ella, repercutiendo en la misma la coyuntura política, social, económica y cultural imperante en las distintas épocas.

La educación, fenómeno que se explica dentro de un entorno social determinado, puede actuar como agente dinámico o retardatario en la evolución de los grupos humanos. En general, entre los siglos $\vee$ y IV a.C. la población griega presentaba niveles muy bajos de instrucción; leer y escribir eran habilidades que sólo unos pocos poseían, mientras que la gran mayoría respondía a los dictados de la cultura oral. Pero en las postrimerías del siglo Iv a.C. surgió en Grecia un nuevo horizonte histórico, estableciéndose y transformándose instituciones docentes, y aconteciendo un notable ascenso de los niveles de alfabetización e instrucción.

En este orden de cosas, el término analfabeto se asocia al individuo que no es capaz de leer un texto. Por ende, el concepto de alfabetización es la capacitación o aprendizaje que faculta a una persona para poder leer y escribir. En la Antigüedad, el aprendizaje de la escritura no era paralelo, sino posterior, al de la lectura. Por ello, parece lógico pensar que todos los que rubricaban supieran leer, pero no al revés, constatando el análisis de la documentación que no siempre una firma es sinónimo de que el signatario supiera escribir.

La historia de la Educación griega es frecuentemente presentada como un proceso evolutivo lineal, desde los hitos culturales de época homérica, a través de banquetes, ritos de paso y competiciones atléticas, hasta los focos intelectuales de las primeras escuelas, una progresión que, en términos de Marrou, se produce desde el héroe aristocrático al escriba, desde el cultivo del cuerpo al cultivo de la razón ${ }^{18}$. Pero este proceso, cuya verdadera evolución puede ser calificada en «dientes de sierra», va íntimamente parejo al desarrollo de la polis griega, y de su necesidad de formar ciudadanos capacitados para participar racionalmente en la dinámica política.

Aunque el análisis del presente trabajo contempla de manera preferente el desarrollo del pensamiento y de las realizaciones educativas durante los periodos clásico y helenístico, es preciso abordar determinados aspectos relativos a etapas más tempranas y tardías, ofreciendo, de este modo, una visión global.

La teoría y el método educativo no aparecen en Grecia, durante los siglos $v$ y IV a.C., de forma destacada y autónoma, sino que lo hacen en un papel secundario, de la mano de la filosofía y del pensamiento político. En la Antigüedad griega, la educación no constituía un fin en sí misma, sino un medio para alcanzar determinado estado de cosas. Tomando como base la afirmación aristotélica sobre una de las dimensiones vitales del individuo -el hombre, por naturaleza, es un animal político- ${ }^{19}$ la polis surge como una forma de vida bajo el perfil de una comu-

\footnotetext{
18 Marrou, H. I., Op. cit.

19 Aristóteles: Política, 1253a: «Según esto es, pues, evidente, que la ciudad-estado es una cosa natural y que el hombre es por naturaleza un animal político o social; [....] Y la razón por la que el hombre es un animal político (zôon politikón) en mayor grado que cualquier abeja o cualquier animal grega-
} 
nidad política. De la necesidad de agruparse y vivir conjuntamente, el individuo desarrolla un lenguaje y un código moral determinados, superando los estadios familiar y aldeano hasta configurar un verdadero estado.

La ciudad-estado griega, como el resto, surge y se consolida mediante la existencia de un pacto, de un acuerdo, para la consecución de una serie de objetivos, ya sean políticos, sociales o económicos: el bien común. Por esta razón, la educación nacería de la mano del pacto como mecanismo reproductivo del mismo, estando orientada a su fortalecimiento, y fomentando una serie de valores e ideales. Éstos, que conforman la cultura, no forman parte del equipamiento natural del hombre, sino que es necesario aprenderlos. La educación, por tanto, no es una propiedad individual, pertenece a la comunidad, siendo el producto de la conciencia viva de una norma que rige una colectividad, cambiando y transformándose condicionada por la mudanza de los valores válidos para cada sociedad.

A pesar de que la «escolarización» no era un requerimiento legal en la Antigua Grecia, escenas pintadas en vasos del año 500 a.C. nos muestran que, la misma, estaba ampliamente extendida. En líneas generales, y considerando que en sus momentos iniciales fue una cuestión de status socioeconómico elevado, los atenienses emprendían su educación a la edad de siete años, de la mano de un paidagoogós, tras escuchar las hazañas de dioses y héroes de labios de sus padres ${ }^{20}$. Los más humildes abandonaban su instrucción a los tres o cuatro años con una idea de lo básico, mientras que los niños de las familias más pudientes proseguían su formación durante un periodo de diez años. En esta etapa, los niños aprendían bajo la tutela de tres tipos de maestros: los de gramática, que enseñaban lectura, escritura, aritmética y literatura; los paidotribes, maestros de lucha, boxeo y gimnasia; y los kitharistes, que enseñaban música, especialmente canto y ejecución de la lira. Tras todo ello, a la edad de 18 años, los varones debían someterse a dos años de entrenamiento militar, después de los cuales regresaban a la educación superior que los preparaba para la vida pública.

Tradicionalmente, el origen de la educación griega se sitúa en el seno de la institución familiar. Esta iniciativa, de carácter privado, fue rápidamente acaparada por los diferentes clubes aristocráticos, hetairas, existentes en el interior de las incipientes comunidades políticas, siendo el banquete su máximo producto cultural, difusor de la virtud e ideales aristocráticos. Trayendo a colación las palabras de M. A. Galino $^{21}$, «...en un principio la educación es únicamente patrimonio de los nobles,

\footnotetext{
rio es evidente. La naturaleza, en efecto, según decimos, no hace nada sin un fin determinado; y el hombre es el único entre los animales que posee el don del lenguaje. La simple voz, es verdad, puede indicar pena y placer y, por tanto, la poseen también los demás animales - ya que su naturaleza se ha desarrollado hasta el punto de tener sensaciones de lo que es penoso o agradable y de poder significar esto los unos a los otros-; pero el lenguaje tiene el fin de indicar lo provechoso y lo nocivo y, por consiguiente, también lo justo y lo injusto, ya que es particular propiedad del hombre, que lo distingue de los demás animales, el ser el único que tiene la percepción del bien y del mal, de lo justo y lo injusto y de las demás cualidades morales, y es la comunidad y participación en estas cosas lo que hace una familia y una ciudad-estado.»

20 Golden, M., Op. cit.

21 Galino, M. A., Op. cit.
} 
que representan la clase directora en el poder político y la depositaria de la cultura, en tanto que la masa popular, con la que la aristocracia mantiene una relación patriarcal, está desprovista de todo derecho...». Pero no es hasta la aparición de los sofistas, considerados el origen de la verdadera educación y de las bases de la pedagogía, cuando arranque una corriente de pensamiento educativo que fructificará en época clásica y helenística.

La nueva concepción y configuración política, la democracia, requería un nuevo "sistema educativo» que sustituyera a la areté aristocrática y satisficiera los nuevos ideales ciudadanos. Fue el momento exacto en el que la iniciativa privada fue perdiendo peso frente a la iniciativa pública, extendiendo el Estado la educación desde la comunidad de sangre a todo ciudadano libre. De esta manera surgió el concepto de paideia, medio de superación de los privilegios de la antigua educación aristocrática.

La sofística constituyó un movimiento que publicitó y extendió a amplios grupos de población la exigencia de una areté fundada en el saber, no en la sangre, originando una fuerte polémica sobre la posibilidad de enseñar la virtud. Coincidente con un interés de la filosofía en el individuo, y no en naturaleza, la finalidad del movimiento sofístico no fue la educación del pueblo sino la educación de los dirigentes políticos, empleando la elocuencia para tal finalidad. Su actividad, lejos de valoraciones juiciosas, suscitó la reacción intelectual de Sócrates y de Platón ${ }^{22}$. Sus obras, como contestación a su práctica educativa, no se entienden sin su existencia.

Los sofistas, considerados los primeros profesionales de la enseñanza, al impartir su conocimiento mediante el cobro de su actividad, se autodefinían como maestros y críticos de la cultura. Asumieron como oficio el ser maestros de areté, impartiendo un proyecto definido y sistemático, de carácter humanístico, basado en el dominio de la palabra, poseedora del poder de la persuasión. Fueron duramente criticados ${ }^{23}$, desde posiciones académicas, al entenderse la retórica no como una herramienta de producción de saber, sino como un vehículo de adulación de las masas que establecía saberes aparentes. Platón reprochaba a los sofistas el hecho de que sólo enseñaran medios para alcanzar un fin, sin reparar en las exigencias de la moral. Los acusaba de ofrecer el triunfo para el razonamiento débil sobre el más fuerte, de hacer prevalecer la apariencia sobre la realidad. Aristóteles, heredero de la crítica platónica, definía la sofística como un arte de la apariencia, completamente ajeno a la verdadera sabiduría, y al sofista como aquel que comerciaba con una sabiduría figurada y no real. Pero pasa desapercibido que fueron pensadores de gran capacidad, innovadores sociales de evidente influencia, y maestros con un sólido manejo del saber de su tiempo ${ }^{24}$.

22 López, R.: «Sofistas griegos: nuevos maestros, viejos maestros», Ars Brevis, 2, (1996), pp. 251-278.

23 Plácido, D., Op. cit.

24 López, R., Ibídem., p. 253. 
La mayor parte de la información que sobre los sofistas es indirecta y fragmentaria. Con todo, parece haber buenas razones para sostener una nueva interpretación sobre el papel de los primeros sofistas, y reconocer en ellos la categoría de educadores y la condición de innovadores sociales ${ }^{25}$. En este sentido, hay bases sólidas para identificar una primera generación de sofistas, diferente de todas las siguientes, compuesta por pensadores de gran nivel y educadores originales, entre los cuales, pese a sus diferencias, existía un núcleo común que les otorgaba una identidad específica:

- Un interés por el ser humano y la sociedad, relacionado con la creciente reflexión sobre el fenómeno de la civilización y de la cultura.

- El mantenimiento de una posición relativista, tanto en la posibilidad del conocimiento como en lo referente a las formas de organización social y política del individuo.

- Una distinción entre leyes sociales (nómos), consideradas un producto humano, y leyes de la naturaleza (physis).

- Un interés por la retórica y la erística en una sociedad democrática en la que el dominio de la palabra y del discurso significaba el éxito y la consideración de sus miembros.

- Una finalidad práctica resultante de enseñar el arte de vivir y gobernar.

En este grupo se incluyen los cinco pensadores tradicionales: Protágoras de Abdera, Gorgias de Leontini, Pródico de Ceos, Hipias de Elis y Trasímaco de Calcedonia. Maestros itinerantes llegados a Atenas, sus recorridos debieron ser el crisol en el que se forjó ese espíritu de pensadores libres y transgresores. Buenos conocedores de la tradición filosófica y cultural helénica, mantuvieron un interés por el lenguaje que resultaba decisivo en sus aspiraciones de éxito ${ }^{26}$.

Los sofistas provocaron profundos cambios en el modo de pensar y en las costumbres de su época, respondiendo con una propuesta muy concreta a las nuevas exigencias de la política ateniense surgidas después de las Guerras Médicas. La educación que recibían los jóvenes, centrada en las habilidades elementales de leer, calcular y escribir, junto con la formación gimnástica y musical, comenzó a resultar insuficiente frente a los mayores requerimientos que planteaba la ciudadanía, la participación política y las pretensiones de una actividad intelectual más extensa. Ésta dio paso a una nueva, cimentada en la gramática, la dialéctica y la retórica ${ }^{27}$.

Con seguridad fue Atenas la ciudad más culta de su tiempo, la verdadera capital intelectual de Grecia. A diferencia de lo que ocurría en Oriente o Egipto, en donde la educación formal estaba destinada a determinadas minorías selectas, en Atenas se buscó favorecer la preparación de todos los hombres libres a fin de que

\footnotetext{
25 López, R., Op. cit., p. 251-278.

26 López, R., Op. cit., p. 255.

27 Como perfección del lenguaje, del pensamiento y de la palabra, respectivamente.
} 
pudiesen dar cumplimiento a sus deberes como ciudadanos. Atenas poseía una sensibilidad bien desarrollada respecto de la importancia de la educación, pero carecía de una institución de educación superior. En esas condiciones, los sofistas introdujeron una forma de educación de características inéditas, independiente del Estado, apoyada en una relación formalizada entre maestro y discípulo, y en el uso sistemático del libro. Todo esto en el marco del recién incorporado concepto de honorario ${ }^{28}$.

Hegel ${ }^{29}$ sostenía que poetas y rapsodas ${ }^{30}$ fueron sustituíos por los sofistas como interlocutores del saber, acabando con la era de la creencia y de la fe. El mismo Platón reconoció su influencia, llegando a afirmar que fue Homero quien educó a la Hélade. Toda esa tradición fue removida, no sin conflicto, por los sofistas, creando una nueva cultura en donde el pensamiento, y ya no el respeto a la autoridad consagrada, orientaba la vida de los individuos ${ }^{31}$.

Como bien argumenta Jaeger ${ }^{32}$, hay un mérito adicional en los sofistas: «ellos son los creadores de una concepción consciente de la educación, proceso que debía asumirse de un modo resuelto y como una tarea sostenida en el tiempo, vinculada a la formación del espíritu». En uno de los fragmentos del texto Sobre la Concordia de Antifón se lee:

«...Lo primero para los hombres, creo que es la educación, pues si alguien realiza el comienzo de algo correctamente es casi seguro que si fin será excelente. Según la siembra así ha de ser la cosecha. Y si se deposita en un cuerpo joven la simiente de una auténtica formación ésta vive y florece a través de toda su existencia y ni la lluvia ni la sequía la destruyen...». La noción de futuro, implícita en el discurso, fue el punto de partida para llegar a una concepción de la formación ciudadana como un objetivo superior, en la cual el Estado tenía una decidida responsabilidad centrada en la posesión del respeto y de la justicia. En este sentido, la política no era una opción que el individuo pudiera o no tomar, constituía, sencillamente, la actividad social fundamental.

El siglo Iv a.C., tras la Guerra del Peloponeso, presenció la reconstrucción interior y exterior de Grecia. La nueva generación tenía ante sí el desafío de recuperar el esplendor griego, siendo la paideia su motor. No se trataba solamente de reformar el Estado a partir de la formación del individuo. Se trataba de formar a quienes gobernaban al pueblo y, a través de estos líderes, al pueblo mismo. Y este contexto, en el seno de la necesidad de intervención en la vida pública, fue el caldo de cultivo óptimo para que Platón, Isócrates y Aristóteles reflexionaran sobre el individuo y sobre los problemas que planteaba su vida en comunidad, al tiempo que transmitían, en el sentido más pedagógico del término, sus enseñanzas a otros.

\footnotetext{
28 López, R., Ídem., p. 256.

29 Hegel, G.: Lecciones Sobre Historia de la Filosofía, México, F.C.E., 1985

30 Los poetas habrían aportado, a través de sus relatos y de sus personajes divinos y humanos, los ejemplos señeros, las normas básicas de conducta y los ideales de vida.

31 López, R., Op. cit., p. 254.

32 Jaeger, W., Op. cit.
} 
Platón (428-347 a.C.) estaba destinado, por educación y nacimiento, a participar en la política de Atenas. Su obra filosófica y literaria ha llegado hasta nosotros a través, fundamentalmente, de sus diálogos morales y políticos, donde el Político, las Leyes y la República ocupan un lugar privilegiado.

Para referirnos a la íntima relación que entre Política y Educación se desprende de la obra de Platón es necesario hacer referencia a su obra la República. Dividida en diez libros, sienta las bases para la consecución de una sociedad urbana, justa y armónica, fundada en una jerarquía de virtudes y en la supremacía de la razón. Platón supeditaba el buen gobierno a la buena educación, expresado en los siguientes términos por Galino ${ }^{33}$ : «...El individuo se construye un estado a su imagen y semejanza, y el estado, a su vez, proporciona al individuo la paideia que conviene a su estilo, la única que puede darle, la que se deriva del ethos de sus instituciones...».

Platón ${ }^{34}$ comprendió que la educación del individuo, y en especial la del gobernante, era el único camino para llegar a conformar una sociedad justa. Sólo quien viviera en el diálogo directo con lo inteligible, poseía la mirada profunda que necesita el hombre de Estado para conducir la sociedad real hacia la sociedad ideal.

La antropología platónica ${ }^{35}$ se debe, en parte, a la influencia que sobre ella ejerció una corriente filosófico-religiosa portadora de una nueva concepción del alma, de la vida y de la muerte: el orfismo ${ }^{36}$. Según ésta, el individuo debía aprender a liberarse de las ataduras del cuerpo. El camino para alcanzar dicha liberación consistía en comprender que el mundo sensible era sólo una imagen confusa del verdaderamente real. La educación según Platón sería, por tanto, desalienación, el proceso que permitía al ser humano tomar conciencia de la existencia de otra realidad, más plena, a la que está llamado, de la que procedía y hacia la que se dirigía.

En el Fedro, Platón compara el alma humana con un carro alado tirado por caballos y conducido por un auriga. El auriga representaría a la razón, mientras que los dos caballos a las partes concupiscible e irascible del alma. Este mito es un complemento necesario para comprender cómo entiende Platón la educación. El individuo, por tanto, debía ser formado en la virtud, en el dominio de sí.

En el plano político, Platón concebía la educación según la consideración del Estado como una persona moral. Al igual que los individuos, sólo alcanzaría su plenitud y perfección si se subordinaba a la razón y a la moral. Rigiéndose según la

${ }^{33}$ Galino, M. A., Op. cit.

34 Barrington, L., Op. cit., pp. 23-35.

35 Dorandi, T., Op. cit., pp. 147-163.

36 El credo órfico propone una innovadora interpretación del ser humano, compuesto de un cuerpo y un alma, indestructible que sobrevive y recibe premios o castigos más allá de la muerte. El cuerpo es un mero un alma vestido del alma, un habitáculo temporal, una prisión o incluso una tumba, que en la muerte se desprende de esa envoltura terrena y va al más allá a recibir sus premios o sus castigos, que pueden incluir algunas reencarnaciones o metempsicosis en otros cuerpos — no sólo humanos-, hasta lograr su purificación definitiva y reintegración en la divinidad. 
justicia, según la idea de bien, la sociedad alcanzaría su máxima posibilidad, tornándose perfecta y dichosa. El Estado, por tanto, encontraría en la educación el medio más idóneo para alcanzar su fin: la justicia.

Platón expone en la República un sistema de educación obligatoria, bajo el control del Estado dividido en dos partes: la educación elemental, que comprendería la preparación de los jóvenes hasta la edad de veinte años, y culminaría con el comienzo del servicio militar, y la educación superior, destinada a aquellas personas que integrarían la clase dirigente. Platón consideraba la música y la gimnasia como elementos básicos de la educación, pues tenían por fin educar al alma. Los futuros gobernantes debían ejercitarse en un gran número de ciencias, conviniendo unir a su conocimiento del bien, el de lo bello y el de lo justo.

Un sistema educativo obligatorio, y dirigido por el Estado, fue probablemente la innovación más importante sugerida por Platón ${ }^{37}$, en relación con la práctica ateniense, frente a la costumbre de dejar que cada hombre consiguiese para sus hijos la educación que bien le pareciera o que encontrase en el «mercado». Otra novedad fue el hecho de que incluyese en la educación a las mujeres, pues entendía que gozaban de las mismas capacidades naturales que los hombres.

En definitiva, se trataba de un plan encaminado a conseguir para el Estado toda la capacidad natural de que fuera posible disponer. El sistema educativo platónico, bosquejado en la República, era más bien una reforma de la práctica existente que la invención de un sistema totalmente nuevo. La reforma consistía en combinar la preparación del ciudadano ateniense con la educación controlada por el Estado proporcionada a los jóvenes espartanos, revisando el contenido de ambas.

Isócrates (436-338 a.C. ${ }^{38}$, a diferencia de Platón, sostenía que el conocimiento no era posible, que lo máximo a lo que podía llegar el individuo era a una opinión justa, convirtiendo la retórica en un medio de acción política. Debiendo prescindir de la verdad, el ser humano podía orientarse por las opiniones de los mejores, de donde derivaba la importancia de la retórica. Así, por medio de la educación retórica, el hombre podía adquirir la capacidad de vivir, capacidad que cada individuo debía ir construyendo sobre su propia experiencia, por un ejercicio cotidiano.

La pedagogía isocrática ${ }^{39}$ no alcanzó una presentación metodológica mediante la cual podamos tener un conocimiento claro de los contenidos que impartía en su paideia. Pese a esta dificultad, sabemos que Isócrates aconsejaba la enseñanza de la obediencia, incidiendo en la importancia de una instrucción basada en el amor y el afecto. La paideia isocrática resultó verdaderamente innovadora al aconsejar el conocimiento de los hechos del pasado, tratándose, seguramente, de

37 Rodríguez Adrados, F., Op. cit., pp. 7-26.

38 Poulakos, T. y Depew D., Op. cit.

39 Cahn, M.: «Reading Rhetoric Rhetorically: Isocrates and the Marketing of Insight», Rhetorica, 7, (1989), pp. 121-144. 
un reflejo del progreso de la cultura contemporánea, la cual incluía en sus dominios la obra de los historiadores, promoviendo a Heródoto y a Tucídides a la categoría de clásicos.

Hacia el siglo iv a.C., Isócrates estableció en Atenas su escuela de retórica, de carácter abierto a diferencia de la Academia de Platón. El ciclo de estudios se extendía a lo largo de tres o cuatro años, estando dirigido a la formación de dirigentes políticos. La relación que mantenía el maestro con los discípulos se realizaba en un ambiente de intimidad, para lo cual ayudaba el reducido número de alumnos. En lo que atañe a la enseñanza, el objetivo inmediato era la formación del hombre. El sujeto de la educación era el gobernante, los hombres cultos y el pueblo mismo. Su contenido giraba en torno a la elocuencia, el arte de hablar bien.

Aristóteles (384-322 a.C.), discípulo de Platón, apostó decididamente por la democracia moderada o Politeia, una conjugación de oligarquía y democracia que buscaba el equilibrio entre los elementos cualitativos y cuantitativos. En el libro $X$, Naturaleza del placer y de la felicidad, de su Ética Nicomáquea, reflexionaba sobre cuestiones educativas, señalando que el desarrollo perfecto de la ética alcanzaba su máximo desarrollo en Política. Es precisamente en Política donde se ocupa de forma más completa del tema educativo, vinculando comunidad y educación, pues el fin de la comunidad y del individuo es el mismo, y por tanto ha de ser idéntico el fin propuesto para la mejor comunidad y para el mejor hombre ${ }^{40}$.

A lo largo y ancho de la obra aristotélica subyacen los dos significados atribuidos al concepto de Paideia - cultura y educación-, término que sintetiza la permanente dinámica de interacción voluntaria entre los ideales colectivos y las prácticas individuales, entendido por Aristóteles como un quehacer sintético motor de la excelencia humana ${ }^{41}$.

Para Aristóteles ${ }^{42}$, la educación debía ser pública e igualitaria para todos los ciudadanos libres. Además, debía ser integral, referida al cuerpo -educación física-, al carácter -educación moral- y al conocimiento -educación intelectual-, y estar acomodada a los principios constitucionales del Estado, afectando no sólo a los individuos, sino también a las familias y a la comunidad política.

La gran contribución de Aristóteles ${ }^{43}$ consiste en el modo en que fundamentó y orientó su proyecto educativo. Para comprender, de la mejor manera, este proyecto, Aristóteles decidió construir su sistema pedagógico en base a la respuesta a cuatro cuestiones fundamentales ${ }^{44}$ : para qué se ha de educar, por qué se ha de educar, cómo se ha de educar y a quién corresponde educar.

40 González Hernández, A. y Ayala de la Peña, A.: «Estado y educación en la teoría de la ciudadEstado: la actualidad de dos antecedentes histórico-culturales», Anales de Pedagogía. Revista de la Facultad de Filosofía y Ciencias de la educación, 16, (1998), pp. 9-20.

41 Calvo Martínez, T., Op. cit., pp. 9-22.

42 Aristóteles, Política, VI y VIII.

43 Cappelletti, A. J., Op. cit., pp. 323-328. 


\section{- Para qué se ha de educar}

Según Aristóteles, se ha de educar para la vida, pero no cualquier forma de vida, sino una vida digna de un ser humano. En este sentido, la vida es fundamentalmente actividad. Puesto que todas las actividades, actos y elecciones están orientados a un fin, el último fin que todos perseguimos es la felicidad. Por esta razón, educar para la vida sería educar para la felicidad, modo de vida digno, satisfactorio y adecuado para el ser humano.

Aristóteles distingue dos partes en la naturaleza humana: una parte racional, cuya función es el conocimiento, y una parte irracional, que corresponde a las pasiones. Esta segunda parte debe obedecer a los dictados de la razón para vivir racionalmente, ejercitando la actividad intelectual y acomodando las pasiones y deseos a los dictados de la razón. Por ello, a la primera de estas dos dimensiones correspondería la educación intelectual, mediante la enseñanza y el razonamiento, mientras que a la segunda correspondería la educación moral, llevada a cabo mediante la formación del carácter.

\section{- Por qué se ha de educar}

Para Aristóteles, la educación era necesaria dado lo escaso de nuestra dotación natural. En su opinión, toda enseñanza viene a perfeccionar lo que la naturaleza deja incompleto. Por ello, al individuo había que enseñarle desde la infancia, desde el lenguaje hasta los conocimientos más complejos y los saberes más especializados. Esta sería la función de la educación intelectual, de la educación para el ejercicio de la actividad racional. Además, la educación reportaba hábitos morales o virtudes.

\section{- Cómo se ha de educar}

En el libro VII de la Política, Aristóteles señala los tres factores que inciden en la educación: la naturaleza, el hábito y la razón. La naturaleza, el temperamento y las dotes e inclinaciones naturales de los educandos constituyen un factor fundamental para el éxito de la educación, pero se trata de una condición previa que escapa, en principio, a la acción del educador. Quedan, por tanto, como factores decisivos, el hábito y la razón. Por tal razón, la educación debería comenzar por la formación de los hábitos para, posteriormente, en la medida de lo posible, reforzarlos por medio de la razón.

\section{- A quién corresponde educar}

Por último, Aristóteles concibe la labor educativa como racional, exterior al educando, debiendo estar dotada de fuerza coercitiva. Tal instancia recaería en las le-

\footnotetext{
${ }^{44}$ Calvo Martínez, T., Op. cit., pp. 10-21.
} 
yes, pues las órdenes del padre, ni en general las de ningún hombre, poseían fuerza alguna para obligar ${ }^{45}$. Como consecuencia de este hecho, la educación constituiría una competencia irrenunciable del Estado, de la comunidad política como tal, a través de sus leyes.

Para finalizar, es necesario referir que, a lo largo del siglo IV a.C., paralelamente a esta corriente de pensamiento educativo ${ }^{46}$, se observa el establecimiento de un sistema educativo-militar ${ }^{47}$, novedoso en Atenas hasta ese momento, motivado por la nueva realidad histórica generada tras la derrota ateniense en la Guerra del Peloponeso: la efebía ${ }^{48}$. Constituía el desarrollo de una práctica de adiestramiento militar, a imitación de la existente en Esparta desde época arcaica, suponiendo la adaptación del sistema espartano de instrucción del hoplita a las costumbres y régimen democrático ateniense.

Si bien su origen es oscuro, se data su funcionamiento a partir del año 366 a.C. Su reconstrucción se hace obligada mediante el estudio de determinadas fuentes literarias, siendo Aristóteles fundamental, y de la epigrafía, pues proporciona información sobre su articulación interna a partir del año 334 a.C. Sería preciso avanzar en el conocimiento de esta institución, pues pese a ser una realidad que perdura hasta la conquista romana, y a conservarse un amplio conjunto documental ${ }^{49}$, ha centrado en menor medida la atención de los investigadores.

En definitiva, el «proceso educativo y alfabetizador» en la antigua Atenas, siglos $v$ y IV a.C., resultó ser un fenómeno histórico producto del contexto social, político, económico y cultural en el que se inserta. Dicho desarrollo se distingue, sustancialmente, de etapas precedentes, debido a las nuevas realidades acontecidas, tras las cuales se establece un nuevo orden a afrontar por un individuo nuevo. La respuesta dada por la sociedad coetánea es consecuencia de notables reajustes, relacionados con las necesidades humanas en función de la situación vigente.

La conformación del Estado ateniense, durante el siglo v a.C., constituyó el punto de partida histórico del gran movimiento educador. Por primera vez se planteó el objetivo de formar personas autónomas con capacidad para pensar e intervenir en los asuntos públicos. «Hechos educativos» e «instituciones docentes» nacieron de las necesidades más profundas de la vida del Estado, consistiendo en el saber ideal y la formación completa del cuerpo y del espíritu.

La ciudad-estado determinó, por tanto, el tipo de formación que se requería para el ejercicio de las posibilidades que la democracia ateniense demandaba. Pese a ello, como apunta Galino ${ }^{50}$, «...la educación del hombre, que para los

45 Fullat, O.: Política de educación: Politeia-Paideia, Barcelona, CEAC, 1994.

46 Payá Martínez, I.: «La pedagogía ético-política en el pensamiento isocrático», Daimon. Revista de Filosofía, 30, (2003), pp. 49-58.

47 Pélékidis, C., Op. cit.

48 Dumont, A.: Essai sur l'éphébie attique, Osnabrück, Otto Zeller, 1968.

49 Reinmuth, O. W., Op. cit.

50 Galino, M. A., Op. cit. 
griegos es el problema vital por excelencia, reviste un carácter enteramente político que no coarta, sin embargo, la iniciativa, la capacidad creadora y los puntos de vista personales, siempre y cuando éstos armonicen con el sentir de la patria...».

\section{BIBLIOGRAFÍA}

AGAZZI, A. (1971): Historia de la Filosofía y de la Pedagogía, I, Alcoy, Marfil.

ALEGRE GORRI, Antonio (1986): La sofística y Sócrates: ascenso y caída de la polis, Barcelona, Montesinos.

ANDERSON, W. (1964): Man's quest for political knowledge. The study and teaching of politics in ancient times, Minneapolis, Univ. Minnesota Pr.

ANDERSON, W. (1966): Ethos and education in Greek music. The evidencie of poetry and philosophy, Cambridge, Harvard University.

ARMSTRONG, E. B. (1953): Plato's Academy, Leeds Philos. Soc.

BARRINGTON, L. (1959): «Plato's theory of education», CL. Journ, 4, $23-35$.

BECK, F. A. G. (1964): Greek education 450-350 B.C., London, Methuen.

BENETTI BRUNELLI, Valeria (1939): Il pensiero educativo della Grecia, Roma.

BOSSEL, F. W. (1896): The School of Plato, its origin, developement, London.

BOWEN, J. (1972): Historia de la Educación Occidental, I, Barcelona, Herder.

BURNET, J. (1920): Greek Philosophy. Thales to Plato, London.

BURY, R. G. (1937): «The Theory of education in Plato's Laws, Rev. Ét. Grecques, 50, 304-320.

CAHN, M. (1989): «Reading Rhetoric Rhetorically: Isocrates and the Marketing of Insight», Rhetorica, 7, 121-144.

CALVO MARTÍNEZ, Tomás (1993): «¿Por qué y cómo educar?: paideía y política en Aristóteles», Daimon: Revista de filosofía, 30: 9-22.

CALVO MARTÍNEZ, Tomás (1995): De los sofistas a Platón: política y pensamiento, Madrid, Ediciones Pedagógicas.

CAPPELLETTI, A. J. (1976): «Ética y política en Aristóteles», Pensamiento: Revista de Investigación e Información filosófica, vol. 32, n. ${ }^{\circ} 127:$ 323-328.

COLE, S. (1996): The Origins of Rhetoric in Ancient Greece, Baltimore, Johns Hopkins University Press.

COX, Cheryl Anne (1998): Household interests: property, marriage strategies, and family dynamics in ancient Athens, Princeton, Princeton University Press.

DIES, A. (1935): Platon, París.

DORANDI, Tiziano (1994): «La Academia de Platón a Antilo: estructura, historia y pensamiento", Endosa, 3, 147-163.

DUMONT, Albert (1968): Essai sur l'éphébie attique, Osnabrück, Otto Zeller.

EGIDO GÁLVEZ, Inmaculada y HERNÁNDEZ BLASI, Carlos (1990): «La educación en Grecia», Cuadernos de Pedagogía, 187, 88-96.

FORBES, G. A. (1929): Greek Physical Education, New York.

FRIEDLANDER, P. (1928): Platon, Eidos, Paideia, Dialogos, Berlín, Leipzig.

FULLAT GENÍS, Octavi (1992): Filosofías de la educación: paideia, Barcelona, CEAC.

FULLAT GENÍS, Octavi (1994): Política de educación: Politeia-Paideia, Barcelona, CEAC.

GALINO, M. A. (1982): Historia de la Educación: Edades Antigua y Media, Madrid, Gredos.

GIRARD, P. (1891): L'éducation athénienne, París.

GOLDEN, Mark (1990): Children and childhood in classical Athens, Baltimore, Johns Hopkins University Press.

GOLDSHMIDT, V. (1947): Les Dialogues de Platon. Structure et Méthodes dialectiques, París, P.U.F. 
GONZÁLEZ HERNÁNDEZ, Ángel y AYALA DE LA PEÑA, Amalia (1998): «Estado y educación en la teoría de la ciudad-Estado: la actualidad de dos antecedentes histórico-culturales", Anales de Pedagogía. Revista de la Facultad de Filosofía y Ciencias de la educación, 16, 9-20.

GUTHRIE, W. K. C. (1967): The Greek Philosophers. From Thales to Aristotle, London, Methuen.

HAVELOCK, Eric. A, (1996): La musa aprende a escribir. Reflexiones sobre oralidad y escritura desde la Antigüedad hasta el presente, Barcelona, Paidós.

HARRIS, H. A. (1972): Sport in Grece and Rome, Thames and Hudson.

HERTER, H. (1952): Platon's Akademie, Univ. Bonn.

ISNARDI, P. M. (1959): «Studi recenti e problemi aperti sulla struttura e la funzione delle prima Accademia platonia», RSI, LXXI, 271-291.

JAEGER, Werner (1996): Paideia: Ios ideales de la cultura griega, Madrid, F.C.E.

KERFERD, George Briscoe (1981): The sophistic movement, Cambridge, University.

KIMBALL, B. A. (1986): Orators and Philosophers: A History, Cambridge, Mass.: Blackwell.

KRAEMER, H. J. (1959): Areté bei Platon und Aristoteles. Zum Wesen und zur Geschichte der platonischen Ontologie, Heidelberger Akad, phil-his KI.

LACEY, W. K. (1968): The family in classical Greece, London, Thames and Hudson.

LANDSBERG, P. L. (1926): La Academia Platónica, Madrid, Rev. de Occidente.

LASSO DE LA VEGA, J. S. (1966): Ideales de la formación griega, Madrid, Rialp.

LIBRIZZI, C. (1950): II problemi fondamentali della filosofia di Platone, Padova.

LODGE, R. C. (1956): The phylosophy of Plato, London.

LÓPEZ, Ricardo (1996): «Sofistas griegos: nuevos maestros, viejos maestros», Ars Brevis, 2, 251-278.

LUZURIAGA, Lorenzo (1984): Historia de la educación y de la pedagogía, Buenos Aires, Losada.

LYNCH, J. P. (1972): Aristotle's school: a study of a Greek educational institution, Los Ángeles, University of California.

MARROU, H. I. (1985): Historia de la Educación en la Antigüedad, Madrid, Akal.

MAS TORRES, Salvador (2003): Ethos y polis: una historia de la filosofía práctica en la Grecia clásica, Tres Cantos, Istmo.

MELERO BELLIDO, Antonio (1996): Sofistas: testimonios y fragmentos, Madrid, Gredos.

MOREAU, J. (1967): Le sens du platonisme, París, Les Belles Lettres.

MORRISON, J. S. (1948): «An introductoru chapter in the history of Greek education», Durham Univ. Juorn., 41, 55-63.

MOUTSOPOULOS, E. (1959): La musique dans l'oeuvre de Platon, París, P.U.F.

OREJA, Fernando (1992): «Aristóteles y la Retórica», Revista de Filosofía, 5 (8), 419-427.

PAILLER, Jean-Marie y PAYEN, Pascal (2004): Que reste-t-il de l'education classique?: relire «le Marrou», histoire de l'éducation dans l'Antiquité, Tolousse, Presses Universitaires de Mirail.

PAYÁ MARTÍNEZ, Isaac (2003): «La pedagogía ético-política en el pensamiento isocrático», Daimon. Revista de Filosofía, 30, 49-58.

PATRUCCO, R. (1972): Lo sport nella Grecia antica, Firenze, L.S. Olschki.

PÉLÉKIDIS, Crisis (1962): Histoire de l'éphébie attique des origines a 31 avant Jésuschrist, París, Editions E. De Boccard.

PHILLIPS, D. Y PRITCHARD, D. (2003): Sport and festival in the ancient Greek world, London, Classical Press of Wales.

PLÁCIDO, D. (1991): «La ciudad de Sócrates y los sofistas: integración y rechazo». En Alvar, Jaime y Gascó, Fernando, Heterodoxos, reformadores y marginados en la Antigüedad clásica, 13-28.

POULAKOS, Takis y Depew David (2004): Isocrates and civil education, Austin, University of Texas Press. 
RABBOW, P. (1970): Paidagogia. Die Grundlegung der abendländischen Erziehungskunst in der Sokratik, Gotinga.

REDONDO, E. Y Laspalas, J. (1997): Historia de la Educación I: Edad Antigua, Madrid, Dykinson.

REINMUTH, Oscar William (1971): The Ephebic inscrptions of the fourth century B.C., Leiden, Brill.

ROBB, Kevin (1994): Literacy and paideia in ancient Greece, Oxford, Oxford University Press.

ROBIN, L. (1935): Les grands philosophes. Platon, París, Alcan.

ROBINSON, R. (1953): Plato's Earlier Dialectic, Oxford.

RODRÍGUEZ ADRADOS, Francisco (1985): «Platón y la reforma del hombre», Taula. Quaderns de Pensament, 3, 7-26.

SCHAERER, R. (1969): La question platonicienne. Étude sur les raports de la pensée et de l'expression dans les Dialogues, Neuchâtel.

SEEL, O. (1953): Die Platonische Akademie, Sttutgart.

SCHAERER, René (1969): La question platonicienne. Étude sur les rapports de la pensée et de l'expression dans les Dialogues, Université de Neûchatel, Neûchatel.

SIERRA GONZÁLEZ, Ángela (1989): «Platón, educación y orden institucional», Revista Canaria de Filosofía Social, 3: 141-146.

STENZEL, J. (1973): Plato's Method of Dialectic, New York, Arno Press.

STOKMEIER, P. (1967): «Glaube und Paideia. Zur Begegnung von Christentum und Antike», ThQ, CXLVII, 432-452.

TOO, Yun Lee (2001): Education in Greek and Roman antiquity, Leiden, Brill.

WARDY, R. (1996): The Birth of Rhetoric: Gorgias, Plato, and Their Succesors, London, Routledge. 